\title{
Effects of insulin analogs and glucagon-like pep
receptor agonists on proliferation and cellular energy metabolism in papillary thyroid cancer
}

This article was published in the following Dove Press journal:

OncoTargets and Therapy

Number of times this article has been viewed

\author{
Liang $\mathrm{He}^{1, *}$ \\ Siliang Zhang ${ }^{2, *}$ \\ Xiaowen Zhang ${ }^{3}$ \\ Rui Liu ${ }^{2}$ \\ Haixia Guan ${ }^{2}$ \\ Hao Zhang' \\ 'Department of Thyroid Surgery, \\ The First Hospital of China Medical \\ University, Shenyang, Liaoning, \\ ${ }^{2}$ Department of Endocrinology and \\ Metabolism, The Endocrine Institute \\ and The Liaoning Provincial Key \\ Laboratory of Endocrine Diseases, \\ The First Hospital of China Medical \\ University, Shenyang, Liaoning, \\ ${ }^{3}$ Department of Endocrinology and \\ Metabolism, Drum Tower Hospital \\ Affiliated to Nanjing University \\ Medical School, Nanjing, People's \\ Republic of China \\ *These authors contributed equally \\ to this work
}

Purpose: This study was aimed to investigate the expressions of the insulin receptor (IR), insulin-like growth factor receptor (IGF-1R), and glucagon-like peptide-1 receptor (GLP-1R) in normal thyroid tissue, papillary thyroid cancer (PTC) tissues, and PTC cells, and to examine the possible role of insulin analogs and GLP-1R agonists in cell proliferation and energy metabolism in PTC cells.

Methods: The expressions of IR, IGF-1R, and GLP-1R in PTC tissues and PTC cell lines were detected by immunohistochemistry and western blotting, respectively. Cell proliferation was evaluated by the 3-(4,5-dimethylthiazol-2-yl)-2,5-diphenyltetrazolium bromide assay. Levels of members of the phosphoinositol-3 kinase/AKT serine/threonine kinase (Akt) and mitogenactivated protein kinase/extracellular signal-regulated kinase (Erk) signaling pathways were measured by western blotting. Energy metabolism of PTC cell lines was analyzed using a Seahorse Extracellular Flux analyzer.

Results: Three receptors could be detected in both PTC tissues and PTC cell lines. Expressions of IGF-1R and GLP-1R were more obvious in PTC than in normal thyroid cells. Neither insulin, four insulin analogs, and two GLP-1R agonists showed significant effects on the proliferation of PTC cells, nor did they influence the levels of Akt/p-Akt and Erk/p-Erk. None of these antidiabetic agents could change the mitochondrial respiration and glycolysis levels in PTC cell lines.

Conclusion: Both PTC tissues and the PTC cell lines express IR, IGF-1R, and GLP-1R. However, insulin analogs and GLP-1R agonists, which are commonly used to treat patients with diabetes, may not influence cell proliferation, the phosphoinositol-3 kinase/Akt and mitogenactivated protein kinase/Erk pathways, or energy metabolism in PTC cells. For now, it is not necessary to avoid use of these antidiabetic agents in patients with PTC.

Keywords: insulin analog, GLP-1R agonist, diabetes mellitus, papillary thyroid cancer

\section{Plain language summary}

Previous studies have expressed concerns that insulin, insulin analogs, and glucagon-like peptide-1 receptor (GLP-1R) agonists might contribute to increased risk of some types of cancer. The present study showed that although insulin receptor, insulin-like growth factor receptor, and GLP-1R are expressed in papillary thyroid cancer (PTC) tissues and PTC cell lines, natural insulin, insulin analogs, and GLP-1R agonists did not show the potential to accelerate the development of PTC cells. Thus, for now, it is not necessary to avoid the use of these antidiabetic agents in patients with PTC.

\section{Introduction}

The incidence of thyroid cancer has been increasing for more than a decade in China. ${ }^{1}$ Among various types of thyroid cancer, papillary thyroid cancer (PTC) is the 
most common. The rapid progress in diagnostic technology might have caused a detection bias; however, it cannot fully explain the rising incidence. Recent studies have found that compared with nondiabetic patients, patients with diabetes have higher risks of cancers originating from several organs, including thyroid cancer. ${ }^{2-8}$ In patients with diabetes, there are some potential factors that may result in the stimulation of mitogenic pathways, forming a link between diabetes and thyroid cancer. ${ }^{9}$ Among them, antidiabetic medications, especially insulin and insulin analogs, are suspected to play a role in the development of cancer. ${ }^{10}$ Moreover, because preclinical research has indicated that a glucagon-like peptide-1 receptor (GLP-1R) agonist, liraglutide, could increase the incidence of medullary thyroid cancer in rodents, these data drew attention to the safety of GLP-1R agonists in PTC patients. However, little evidence in humans has been provided, and the available results are controversial.

Natural insulin is short acting. Insulin analogs made by genetic engineering, which modify the form of natural insulin, alter its absorption, distribution, metabolism, and excretion. GLP-1R agonists are a type of incretin-based drugs. They can mimic the actions of GLP-1 and stimulate insulin release in response to the enteric glucose load. ${ }^{11}$ Both insulin and GLP-1 might work through the phosphoinositol-3 kinase/AKT serine/threonine kinase (PI3K/Akt) pathway and/or mitogen-activated protein kinase/extracellular signal-regulated kinase (MAPK/Erk) pathway. ${ }^{12}$ These two signaling pathways are also critical in regulating cell growth and proliferation; accordingly, they are closely related to cancer, including PTC. Thus, we asked whether insulin analogs and GLP-1R agonists could stimulate these signaling pathways. In addition, cell energy metabolism contributes to the occurrence and development of cancer. The significance of the Warburg effect is not only to provide adequate energy sources for cancer cells, but also to activate proliferation signaling. Therefore, it would be interesting to determine whether insulin analogs and GLP-1R agonists are capable of affecting cell energy metabolism in human PTC.

Thus, the aims of the present study were as follows: first, to detect the expressions of the insulin receptor (IR), insulin-like growth factor receptor (IGF-1R), and GLP-1R in human thyroid tissues and human PTC cell lines; second, to investigate whether natural insulin, insulin analogs, and GLP-1R agonists have an increased mitogenic potency in PTC cell lines; third, to characterize whether the PI3K and MAPK pathways are activated by the studied antidiabetic medications in PTC cell lines; and last, to evaluate the effects of these antidiabetic medications on energy metabolism in PTC cell lines.

\section{Materials and methods PTC tissues, primary thyroid cells, and PTC cell lines}

Human thyroid tissues were obtained from archived formalinfixed, paraffin-embedded tissue blocks, which were stored in the Department of Pathology, the First Hospital of the China Medical University (Shenyang, Liaoning, People's Republic of China). Fifty-two PTCs and 55 matched normal thyroid samples were included. All the data were anonymized.

For primary thyrocytes culture, normal thyroid tissues were obtained as surgical wastes from five patients undergoing thyroidectomies for treatment, stored in sterilized precooled PBS, and transported to the laboratory at $4^{\circ} \mathrm{C}$. Informed consent was obtained from all the participants. The tissue was processed as previously described. ${ }^{13}$ Cells were cultured at $37^{\circ} \mathrm{C}$ in Roswell Park Memorial Institute (RPMI) 1640 medium with $10 \%$ fetal bovine serum (FBS).

The PTC cell line IHH-4 was obtained from the Japanese Collection of Research Bioresources, Japan. The PTC cell line BCPAP was purchased from the DSMZ-Deutsche Sammlung von Mikroorganismen und Zellkulturen $\mathrm{GmbH}$ (German Collection of Microorganisms and Cell Cultures, Braunschweig, Germany). The PTC cell line TPC-1 was kindly provided by Dr Bryan R Haugen (Division of Endocrinology, Diabetes and Metabolism, University of Colorado Denver, Aurora, CO, USA). However, detailed information on the subtypes of PTC cell lines used in our study was unclear. IHH4 cells were cultured in Dulbecco's Modified Eagle's Medium (DMEM) and RPMI 1640 medium mixture (1:1) with $10 \%$ FBS and antibiotics $(100 \mathrm{U} / \mathrm{mL}$ penicillin and $100 \mathrm{mg} / \mathrm{mL}$ streptomycin). BCPAP cells were grown in RPMI 1640 supplemented with 10\% FBS and antibiotics. TPC-1 cells were cultured in DMEM with 10\% FBS and antibiotics. All cells were maintained in a $5 \% \mathrm{CO}_{2}$ humidified incubator at $37^{\circ} \mathrm{C}$.

\section{Immunohistochemistry}

Immunohistochemistry (IHC) was carried out following a previously described process. ${ }^{13}$ Monoclonal anti-IGF-1R, anti-IR, and anti-GLP-1R antibodies (Cell Signaling, Danvers, MA, USA) were used in this study, together with a highly sensitive and specific polymer detection system using horseradish peroxidase (Santa Cruz Biotechnology, Dallas, TX, USA). The stainings of IR, IGF-1R, and GLP-1R were assessed using the Remmele immunoreactive score (IRS) by multiplying the level of staining intensity ( $0-3$ points: absent, weak, intermediate, strong) by the percentage of positive tumor cells ( $0-4$ points: cutoffs: $0 \%,<10 \%, 11 \%-50 \%$, $51 \%-80 \%,>80 \%)$. The staining intensity was evaluated 
according to the following scale: negative ( 0 points), weakly positive (1 point), and positive ( $\geq 2$ points).

\section{Natural insulin, insulin analogs, and GLP-IR agonists}

Natural insulin (Lilly, Indianapolis, IN, USA), four insulin analogs (insulin aspart [Novo Nordisk, Bagsværd, Denmark], insulin lispro [Lilly, Indianapolis, IN, USA], insulin detemir [Novo Nordisk, Bagsværd, Denmark], and insulin glargine [Sanofi, Paris, France]), and two GLP-1R agonists (liraglutide [Novo Nordisk, Bagsværd, Denmark] and exenatide [Lilly, Indianapolis, IN, USA]) were used in this study. For the proliferation assay, three different concentrations $(15,150$, and $1,500 \mathrm{nmol} / \mathrm{L})$ of natural insulin or each insulin analog and three different concentrations $(1,10$, and $100 \mathrm{nmol} / \mathrm{L}$ ) of each GLP-1R agonist were tested. For experiments testing the activation of signaling pathways and cell energy metabolism, only the highest concentration of natural insulin $(1,500 \mathrm{nmol} / \mathrm{L})$, insulin analogs $(1,500 \mathrm{nmol} / \mathrm{L})$, and GLP-1R agonists $(100 \mathrm{nmol} / \mathrm{L})$ were tested.

\section{Proliferation assay}

Cells were seeded in 96 -well culture plates at $10^{3}$ cells/well. After being starved for $24 \mathrm{~h}$, cells were incubated with natural insulin, insulin analogs, or GLP-1R agonists at different concentrations as described above. Cell proliferation was evaluated everyday using a 3-(4,5-dimethylthiazol-2-yl)-2,5diphenyltetrazolium bromide (MTT) assay following the manufacturer's protocol (Roche Applied Science, Mannheim, Germany).

\section{Western blotting}

Western blotting was performed as described previously. ${ }^{13}$ The anti-IGF-1R, anti-IR, and Akt and p-Akt antibodies (Cell Signaling) were used at 1:1,000 dilutions. The p-Erk1/2 and Erk1/2 antibodies (both from Cell Signaling) were used at 1:2,000 dilutions. The anti-GLP-1R (Sigma, St Louis, MO, USA) was used at $8 \mu \mathrm{g} / \mathrm{mL}$. The control anti- $\beta$-actin antibody was diluted at 1:1,000 (Zhongshan Golden Bridge, Beijing, China).

\section{Seahorse extracellular flux analysis}

The extracellular flux (XF)96 Extracellular Flux analyzer (Seahorse Biosciences, Billerica, MA, USA) was used to measure the rate of cell metabolism in mitochondrial respiration and glycolysis. According to the manufacturer's protocols, the cellular oxygen consumption rate (OCR) and the extracellular acidification rate (ECAR) were measured, and expressed as $\mathrm{pmol} / \mathrm{min}$ and $\mathrm{mpH} / \mathrm{min}$, respectively.
In specific stress tests, the following final drug concentrations were delivered: oligomycin $(1 \mu \mathrm{M})$, carbonylcyanide p-trifluoromethoxyphenylhydrazone (FCCP) $(0.25 \mu \mathrm{M})$, antimycin $(1 \mu \mathrm{M})$, rotenone $(1 \mu \mathrm{M})$, glucose $(10 \mathrm{mM})$, and 2-deoxy-D-glucose (100 mM).

\section{Statistical analysis}

The chi-square test, analysis of variance (ANOVA) test, or $t$-test was used to compare the IHC data obtained from PTC tissues with that from normal thyroid tissues. $p<0.05$ was considered statistically significant. In vitro experiments were performed in triplicate. Data are shown as the mean \pm SD. One-way ANOVA was used for multigroup comparisons and the $t$-test was used for two-group comparison. Significance was defined as $p<0.05$. Unless indicated, data shown in the figures are representative.

\section{Results \\ Expression of IR, IGF-IR, and GLP-IR in human thyroid tissues and PTC cell lines}

First, we examined the IR, IGF-1R, and GLP-1R levels in 107 human thyroid tissues (52 PTCs and 55 normal thyroid tissues). As shown by IHC, all three receptors could be detected in human PTC tissues. Positive staining of IR was detected in $48 \%(n=27)$ of PTCs and $45 \%(n=25)$ of normal thyroid samples $(p>0.05)$. The mean IRS for IR was not significantly different between PTCs and normal thyroid samples $(4.69 \pm 2.89$ vs $4.06 \pm 2.39, p>0.05)$. Positive staining of IGF-1R was more frequently observed in PTCs than in normal thyroid tissues ( $60 \%$ vs $18 \%, p<0.05)$, with a higher IRS in PTCs $(4.23 \pm 3.52$ vs $1.53 \pm 1.09, p<0.05)$. Positive staining of GLP-1R was detected in only some PTC samples ( $49 \%$, IRS $=3.14 \pm 1.62$ ), but none in normal thyroid samples $(0 \%, \mathrm{IRS}=1.03 \pm 0.54)$. Representative IHC pictures are shown in Figure 1A.

We further examined the levels of the three receptors in primary cultured normal thyrocytes and PTC cell lines by western blotting (Figure 1B). IR, IGF-1R, and GLP-1R were detected in both normal thyroid cells and in PTC cell lines. The levels of IR did not show an obvious difference between normal thyroid cells and PTC cells, whereas PTC cells contained significantly more IGF-1R and GLP-1R PTC cells compared with that in primary cultured normal thyrocytes.

\section{Effects of natural insulin and insulin analogs on the proliferation of PTC cell lines}

After treatment with different concentrations of natural insulin or insulin analogs, MTT assays revealed that the 
A

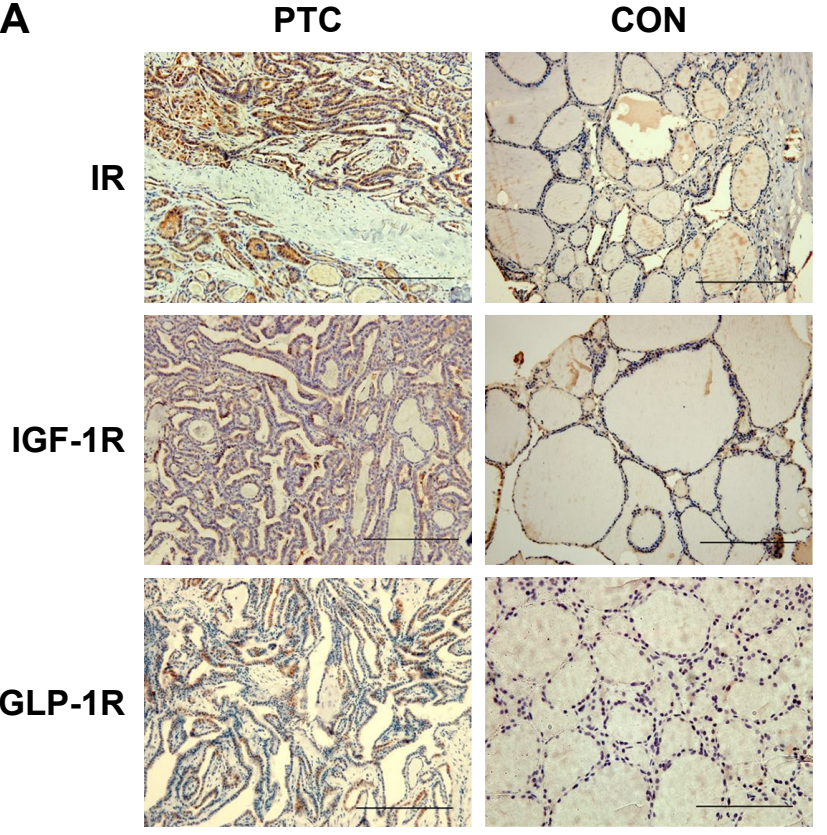

B

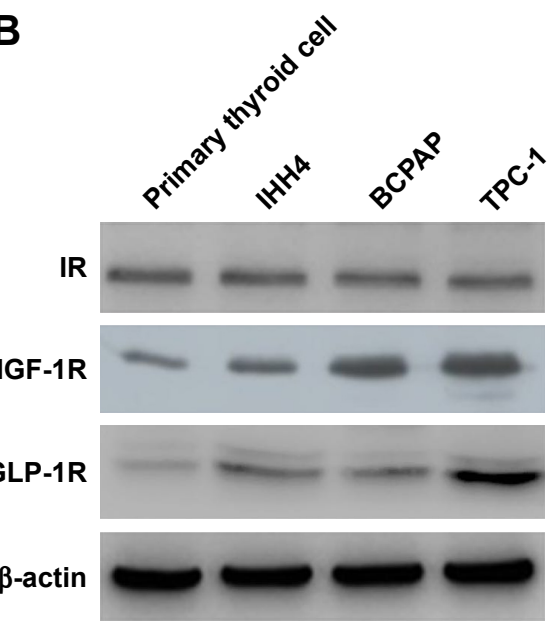

Figure I Expressions of IR, IGF-IR, and GLP-IR in human thyroid tissues and cells.

Notes: (A) IR, IGF-IR, and GLP-IR IHC $(\times 200)$ of PTC and normal tissues. (B) Expression of IR, IGF-IR, and GLP-IR in primary cultured thyrocytes and PTC cell lines. Scale bar $=100 \mu \mathrm{m}$

Abbreviations: GLP-IR, glucagon-like peptide-I receptor; IGF-IR, insulin-like growth factor receptor; IHC, immunohistochemistry; IR, insulin receptor; PTC, papillary thyroid cancer.

treatment did not stimulate significant proliferation of the PTC cell lines used for this study (IHH-4, BCPAP, and TPC-1), although there were slight increases at some concentrations (Figure 2).

\section{Effects of natural insulin and insulin analogs on PI3K/Akt and MAPK/Erk signaling pathways in PTC cell lines}

Activation of the PI3K/Akt and/or MAPK/Erk signaling pathways is related to cell proliferation in PTC; therefore, after treatment with a certain concentration $(1,500 \mathrm{nmol} / \mathrm{L})$ of natural insulin or insulin analogs for $48 \mathrm{~h}$, cells were collected and Akt and Erk, and their active forms p-Akt and p-Erk, were assessed using western blotting. The levels of Akt, Erk, p-Akt, and p-Erk did not change significantly after treatment (Figure 3), indicating that neither natural insulin nor insulin analogs induced aberrant activations of the two signaling pathways in PTC.

\section{Effects of natural insulin and insulin analogs on mitochondrial respiration and glycolysis in PTC cell lines}

Given that cell metabolism is a reflection of cell proliferation, we examined both mitochondrial respiration and glycolysis in PTC cells incubated with or without a high dose
$(1,500 \mathrm{nmol} / \mathrm{L})$ of insulin or insulin analogs for $48 \mathrm{~h}$. The patterns of cell metabolism did not alter in response to treatment with insulin and insulin analogs (Figure 4).

\section{Effects of GLP-IR agonists on the proliferation of PTC cell lines}

As shown in the IHC study, compared with normal thyroid tissues/cells, GLP-1R was overexpressed in human PTC tissues/cells. In this experiment, we tested the effects of liraglutide and exenatide on the proliferation of PTC cell lines using the MTT assay. The results indicated that neither liraglutide nor exenatide could increase the proliferation of PTC cell lines in vitro, irrespective of the GLP-1R agonist concentration and the duration of treatment (Figure 5).

\section{Effects of GLP-IR agonists on PI3K/Akt and MAPK/Erk signaling pathways in PTC cell lines}

After treatment with a certain concentration $(100 \mathrm{nmol} / \mathrm{L})$ of liraglutide or exenatide for $48 \mathrm{~h}$, the levels of key players in the two signaling pathways Akt and Erk, that is, p-Akt and p-Erk, showed no significant alterations in three PTC cell lines (Figure 6), indicating that GLP-1R agonists had little effect on the activation of the two signaling pathways in PTC. 
A

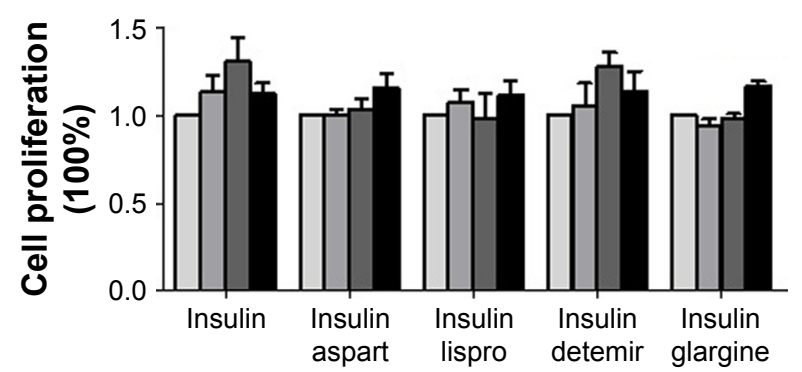

B

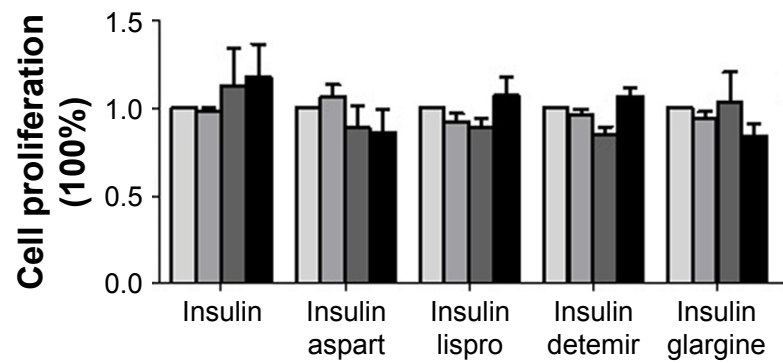

C

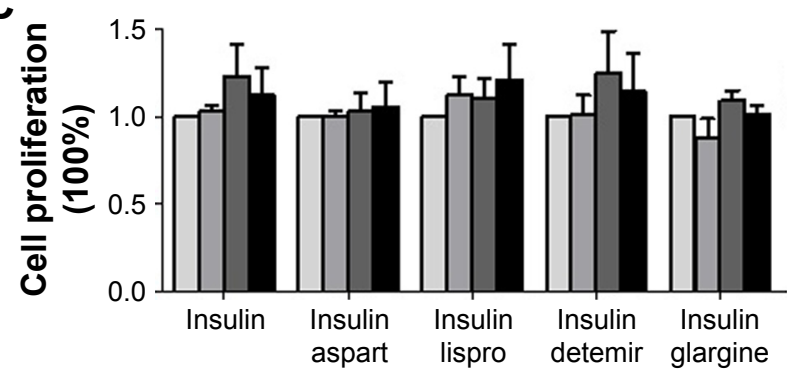

$\square$ Control $\square 15 \mathrm{nmol} / \mathrm{L} \quad \square 150 \mathrm{nmol} / \mathrm{L} \quad \square 1,500 \mathrm{nmol} / \mathrm{L}$

Figure 2 Effects of regular insulin and insulin analogs on the proliferation of PTC cell lines.

Notes: Results from MTT assays at $48 \mathrm{~h}$ after the treatment. (A) IHH4, (B) BCPAP, and (C) TPC-I.

Abbreviations: BCPAP, normal human thyroid cells; IHH4, human papillary thyroid carcinoma cell line; MTT, 3-(4,5-dimethylthiazol-2-yl)-2,5-diphenyltetrazolium bromide; PTC, papillary thyroid cancer; TPC-I, human thyroid cancer cell line.

\section{Effects of GLP-IR agonists on} mitochondrial respiration and glycolysis in PTC cell lines

In PTC cells, mitochondrial respiration and glycolysis were analyzed using the Seahorse XF instrument, in the presence and absence of 48 -h treatment with a high dose $(100 \mathrm{nmol} / \mathrm{L})$ of liraglutide or exenatide. We did not observe any alterations caused by the GLP-1R agonists in energy metabolism in the PTC cell lines (Figure 7).

\section{Discussion}

The effect of antidiabetic drugs on cancer development has raised concerns among researchers, clinicians, patients, and pharmaceutical manufacturers. Previous studies suggested
A

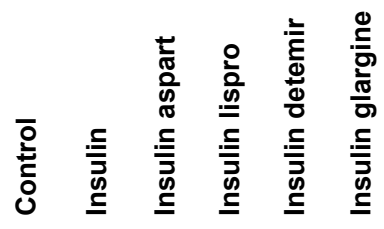

Akt
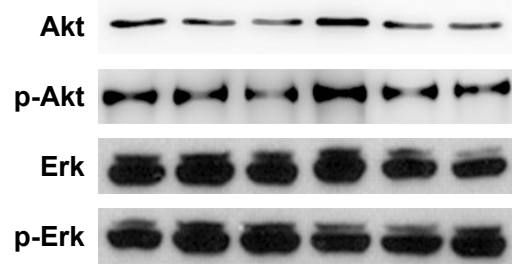

$\beta$-actin
B

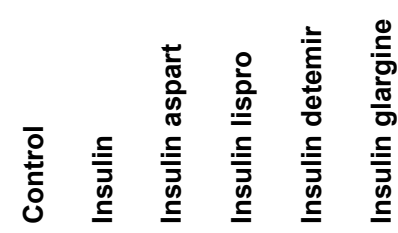

Akt

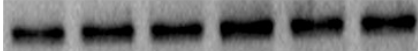

p-Akt

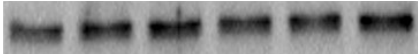

Erk

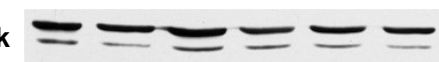

p-Erk $= \pm=$

$\beta$-actin
C

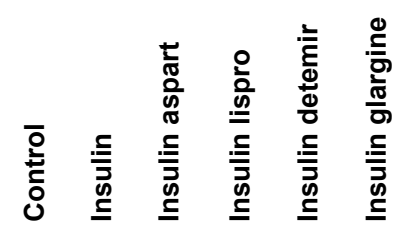

Akt

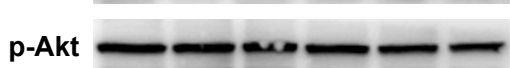

Erk

p-Erk

$\beta$-actin

Figure 3 Effects of regular insulin and insulin analogs on PI3K/Akt and MAPK/Erk signaling pathways in PTC cell lines.

Notes: PTC cells were treated with insulin or each insulin analog at I,500 nmol/L for $48 \mathrm{~h}$. (A) IHH4, (B) BCPAP, and (C) TPC-I.

Abbreviations: Akt, AKT serine/threonine kinase; BCPAP, normal human thyroid cells; Erk, extracellular signal-regulated kinase; IHH4, human papillary thyroid carcinoma cell line; MAPK, mitogen-activated protein kinase; PI3K, phosphoinositol-3 kinase; PTC, papillary thyroid cancer; TPC-I, human thyroid cancer cell line. 

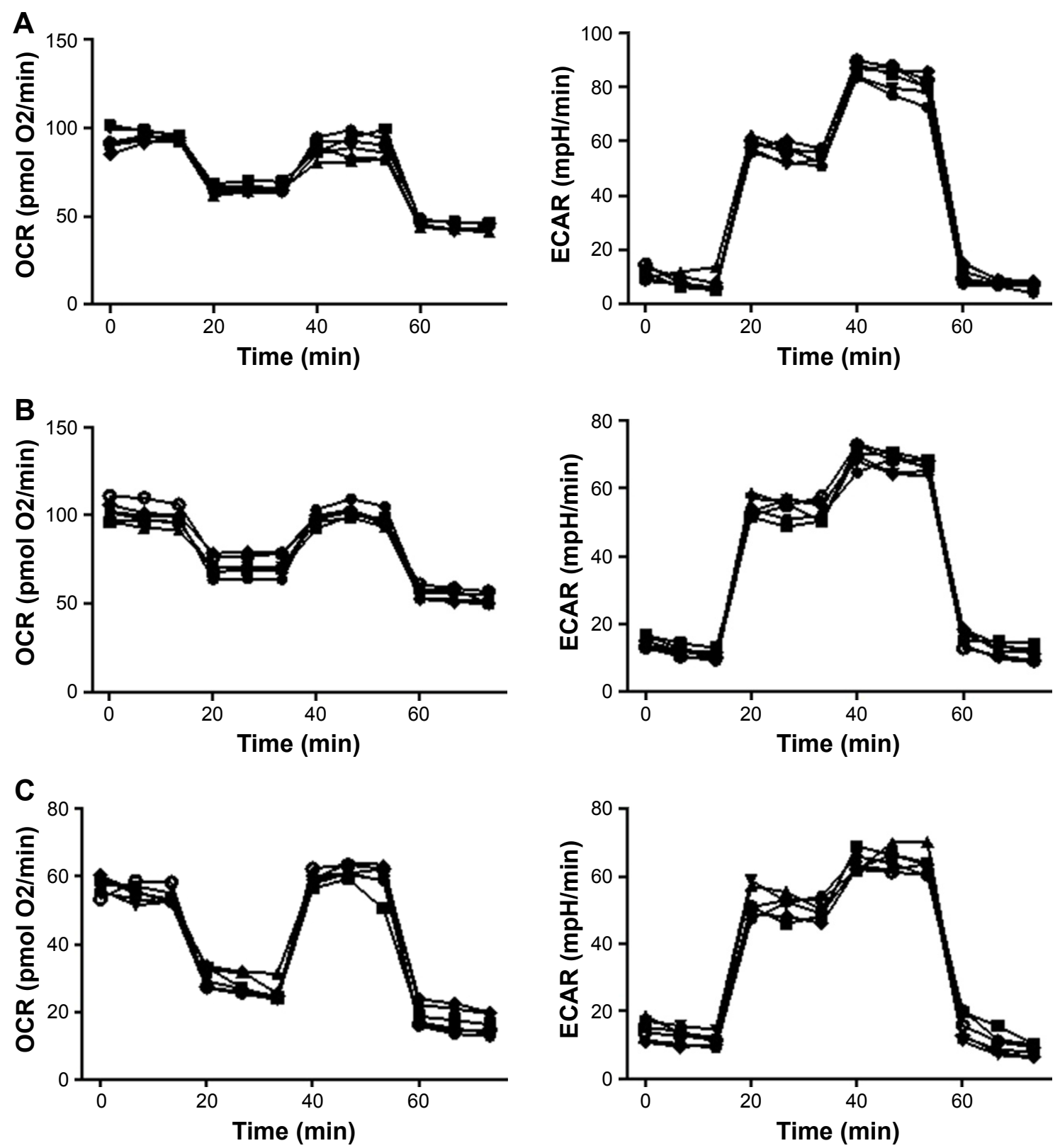

$\rightarrow$ Control $\rightarrow$ Insulin $\leftarrow$ Insulin aspart $\rightarrow$ Insulin lispro $\rightarrow$ Insulin detemir $\rightarrow$ Insulin glargine

Figure 4 Effects of regular insulin and insulin analogs on mitochondrial respiration and glycolysis in PTC cell lines.

Notes: PTC cells were treated with insulin or each insulin analog at I,500 nmol/L for $48 \mathrm{~h}$. Oligomycin (I $\mu \mathrm{M})$, FCCP $(0.25 \mu \mathrm{M})$, rotenone $(\mathrm{I} \mu \mathrm{M})$, and antimycin A (I $\mu \mathrm{M}) \mathrm{were}$ delivered at indicated times to determine different parameters of mitochondrial functions; glucose $(10 \mathrm{mM})$, oligomycin (I.0 $\mu \mathrm{M})$, and 2-deoxy-D-glucose (I00 mM) were delivered at indicated times to determine different parameters of glycolysis status. These drugs were added according to the manufacturer's protocols. (A) IHH4, (B) BCPAP, and (C) TPC-I. Abbreviations: BCPAP, normal human thyroid cells; ECAR, extracellular acidification rate; FCCP, p-trifluoromethoxyphenylhydrazone; IHH4, human papillary thyroid carcinoma cell line; OCR, oxygen consumption rate; PTC, papillary thyroid cancer; TPC-I, human thyroid cancer cell line.

that antidiabetic medications, such as insulin analogs and GLP-1R agonists, might be associated with increased risks of cancers in some sites. ${ }^{14-17}$ Insulin, insulin analogs, and GLP-1R agonists have the potential to stimulate cell proliferation and mitogenic pathways. ${ }^{10,18-20}$ The present study focused on the question of whether insulin analogs and GLP-1R agonists would play a role in the development of
PTC, a common endocrine malignancy. The insulin analogs (insulin aspart, insulin lispro, insulin detemir, and insulin glargine) and GLP-1R agonists (liraglutide and exenatide) tested in the study are widely prescribed for patients with diabetes in current clinical practice. The results of this study showed that IGF-1R and GLP-1R were overexpressed in PTC cell lines; however, the insulin analogs and GLP-1R agonists 
A

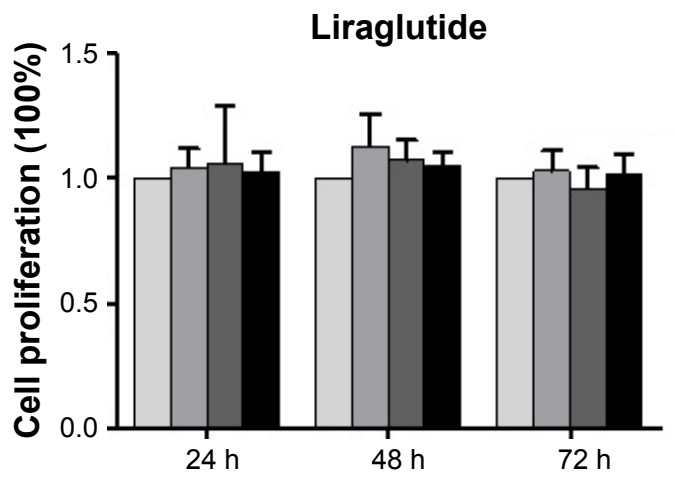

B

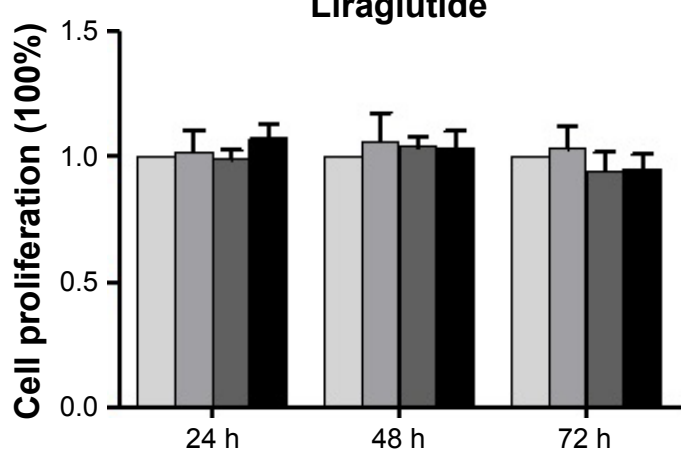

C

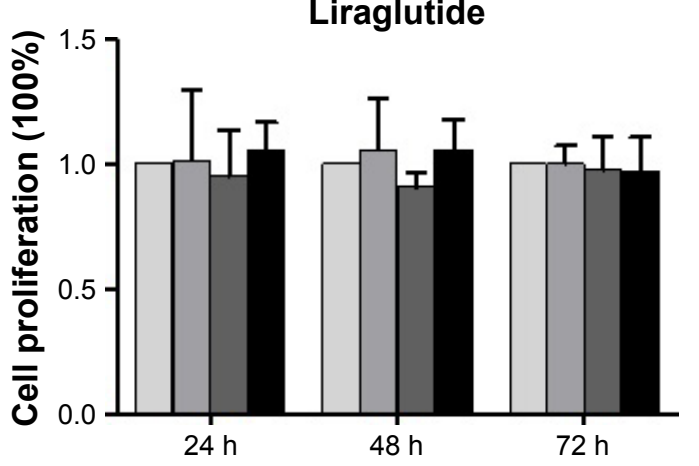

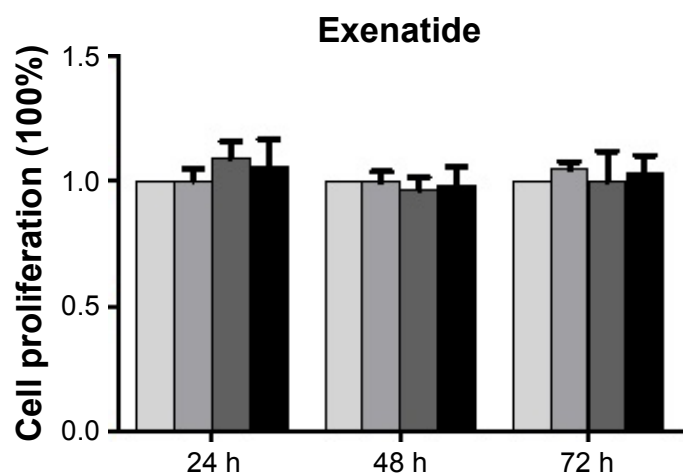

Exenatide

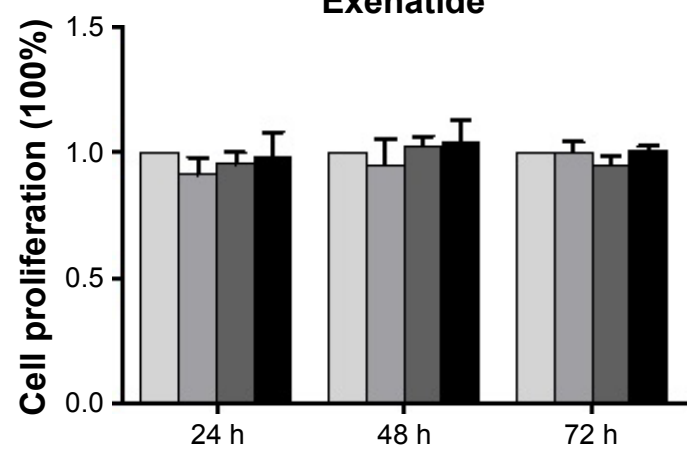

Exenatide

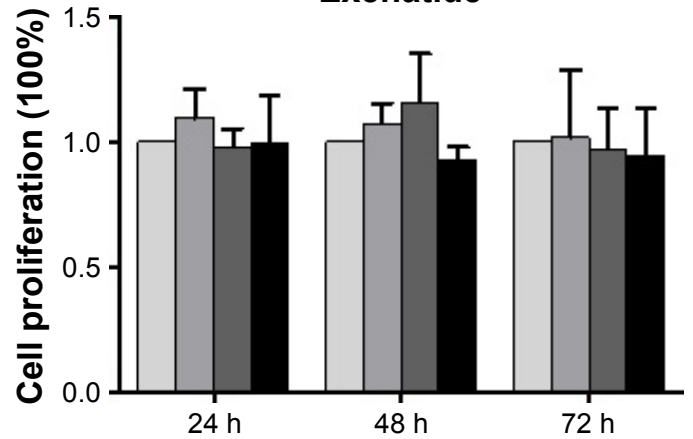

$\square$ Control $\square 1 \mathrm{nmol} / \mathrm{L} \quad \square 10 \mathrm{nmol} / \mathrm{L} \square 100 \mathrm{nmol} / \mathrm{L}$

Figure 5 Effects of GLP-IR agonists on the proliferation of PTC cell lines.

Notes: Results from MTT assays at 24, 48, and $72 \mathrm{~h}$ after the treatment. (A) IHH4, (B) BCPAP, and (C) TPC-I.

Abbreviations: BCPAP, normal human thyroid cells; GLP-IR, glucagon-like peptide-I receptor; IHH4, human papillary thyroid carcinoma cell line; MTT, 3-(4,5dimethylthiazol-2-yl)-2,5-diphenyltetrazolium bromide; PTC, papillary thyroid cancer; TPC-I, human thyroid cancer cell line.

did not increase the proliferation of PTC cells. In addition, these medicines did not activate the PI3K/Akt and MAPK/ Erk signaling pathways, and they did not alter the cell energy metabolism of PTC cells.

In addition to reducing the blood glucose level, insulin is a growth factor for some epithelial tumors. Increased insulin levels also upregulate IGF-1, which is also a growth factor for tumors. Recently, a meta-analysis observed that the use of exogenous human insulin or insulin analogs might be associated with increased risk of cancer in pancreas, liver, kidney, stomach, and the respiratory system. ${ }^{14}$ The potential mechanism is that the insulin or insulin analogs, especially insulin glargine, have a high affinity for IGF-1R and high mitogenic potency. ${ }^{21}$ Thus, insulin and its analogs would favor the development of tumors. Moreover, previous studies found that the IGF-1 system was overactivated in thyroid nodules, which suggested that IGF-1 probably plays an important role in the genesis and development of certain solid thyroid nodules, including PTC. ${ }^{22}$ Schmidt et al also reported that there was a positive association between IGF-1 levels and the risk of differentiated thyroid carcinoma. ${ }^{23}$ Thus, the present study started by detecting IR and IGF-1R in human 

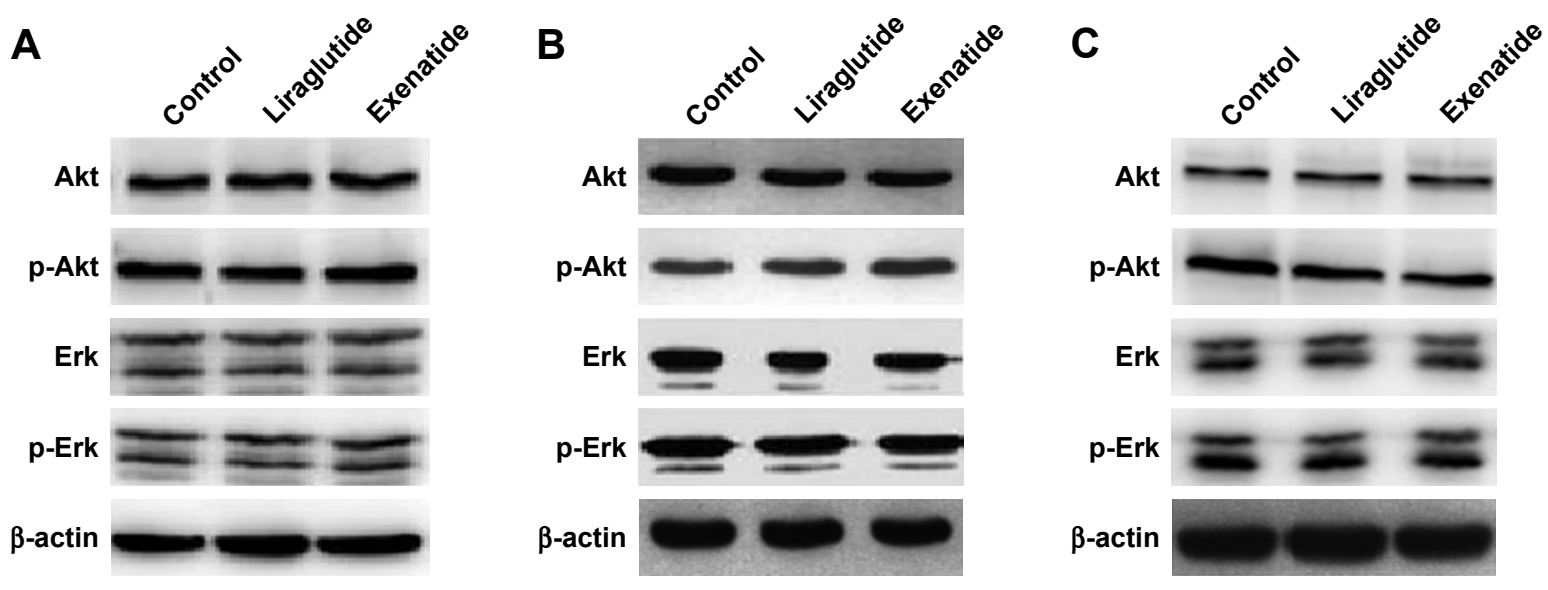

Figure 6 Effects of GLP-IR agonists on PI3K/Akt and MAPK/Erk signaling pathways in PTC cell lines.

Notes: PTC cells were treated with liraglutide or exenatide ( $100 \mathrm{nmol} / \mathrm{L})$ for $48 \mathrm{~h}$. (A) IHH4, (B) BCPAP, and (C) TPC-I.

Abbreviations: Akt, AKT serine/threonine kinase; BCPAP, normal human thyroid cells; Erk, extracellular signal-regulated kinase; GLP-IR, glucagon-like peptide-I receptor; $\mathrm{IHH}$, human papillary thyroid carcinoma cell line; MAPK, mitogen-activated protein kinase; PI3K, phosphoinositol-3 kinase; PTC, papillary thyroid cancer; TPC-I, human thyroid cancer cell line.

thyroid tissues and cells. The results showed that both normal thyroid tissues/cells and PTC tissues/cells expressed IR and IGF-1R. IGF-1R was expressed at a higher level in PTC tissues than in normal thyroid tissues. However, subsequent experiments in vitro indicated that insulin and insulin analogs had no ability to promote the proliferation of PTC cell lines, suggesting that overexpression of IGF-1R in PTC cells would not be a safety concern.

GLP-1R agonists, including liraglutide and exenatide, have been increasingly used for Type 2 diabetes therapy. They work through mechanisms including stimulating the secretion of insulin from the pancreas in a glucose-dependent manner, suppressing the secretion of glucagon, and delaying gastric emptying. Unfortunately, it was observed during the development of liraglutide that it increased the risk of $\mathrm{C}$ cell hyperplasia and might be related to medullary thyroid cancer in rodents. ${ }^{24}$ Thus, GLP-1R activation might contribute to the development of pancreatic cancer and thyroid cancer. ${ }^{24,25}$ In contrast, an in vitro study reported that GLP-1R activation had an antitumor effect on human pancreatic cancers via inhibiting the PI3K/Akt signaling pathway, suggesting that GLP-1-based therapies might be beneficial, rather than harmful, in treating diabetic patients with pancreatic cancer. ${ }^{26}$ These conflicting data questioned the safety of applying GLP-1R agonists for patients who suffered from PTC. In our study, we found that GLP-1R was significantly overexpressed in PTC tissues, but rarely presented in normal tissues, which was consistent with a previous study. ${ }^{27}$ However, when we treated PTC cell lines with GLP-1R agonists in vitro, neither promotion nor inhibition was observed. This result did not support the idea that GLP-1R agonists would accelerate the growth of PTC cells.
As mentioned in the introduction, activation of IGF-1R might result in the activation of the PI3K/Akt and MAPK/ Erk signaling pathways. Moreover, Fang et al and Wei et al indicated that liraglutide stimulated $\beta$-cell proliferation, which is mediated by the PI3K/Akt signaling pathway. ${ }^{28,29} \mathrm{~A}$ study focusing on 3T3-L1 cells found that GLP-1 could promote 3T3-L1 cell proliferation and differentiation via the PI3K/Akt and MAPK/Erk signaling pathways. ${ }^{30}$ Both studies showed that GLP-1-based medicines could influence these signaling pathways, at least in some types of cells. For cancer cells, the $\mathrm{PI} 3 \mathrm{~K} /$ Akt and MAPK/Erk signaling pathways markedly promote protein synthesis, increase cellular proliferation, protect cells from apoptotic stimuli, and participate in the initiation and maintenance of cancer stem cells. ${ }^{31}$ Uncontrolled stimulation along these pathways is closely related to the development of PTC. Thus, to further clarify the safety of insulin analogs and GLP-1R agonists in patients with PTC, we investigated alterations in the PI3K/Akt and MAPK/Erk signaling pathways after treating PTC cells with these agents. According to the expression levels of Akt and Erk, and their active forms p-Akt and p-Erk, we did not find evidence of activation of either pathway by the medicines tested. Unlike previous observations in pancreatic cancer cells, ${ }^{26}$ we did not detect inhibition of either pathway by GLP-1R agonists.

Little data are available about whether energy metabolism in cancer cells is influenced by insulin analogs and GLP-1R agonists. Modifying or reprogramming cellular metabolism is a characteristic of the development of malignancies. This capability can effectively support neoplastic proliferation and help to create a specific tumor microenvironment. For instance, aerobic glycolysis deregulated by the overexpressed pyruvate kinase M2, a key enzyme of 
A

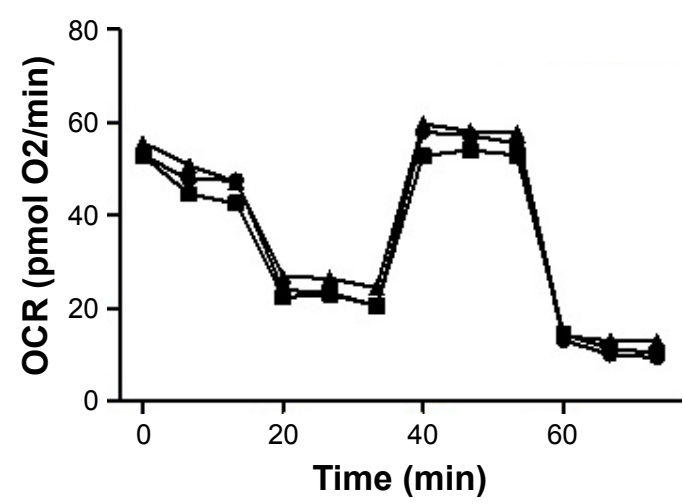

B

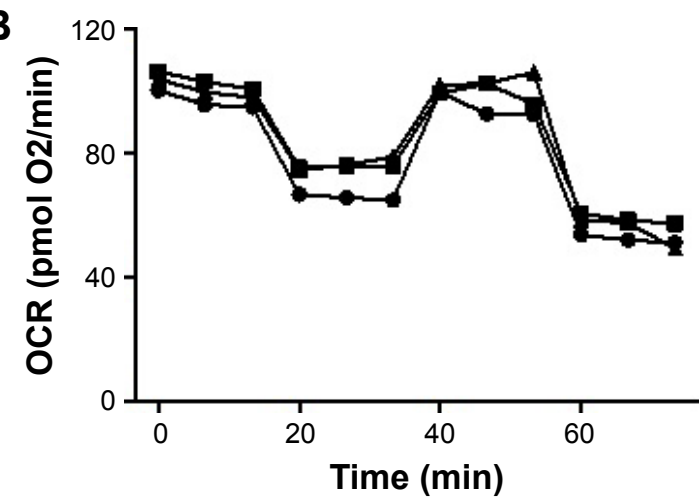

C

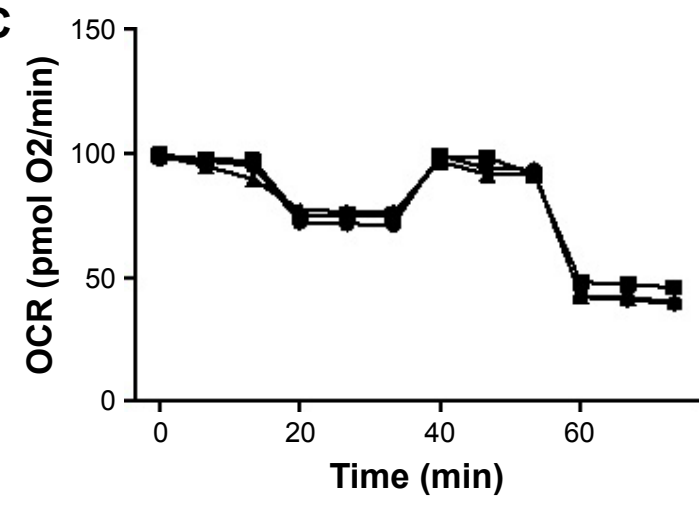

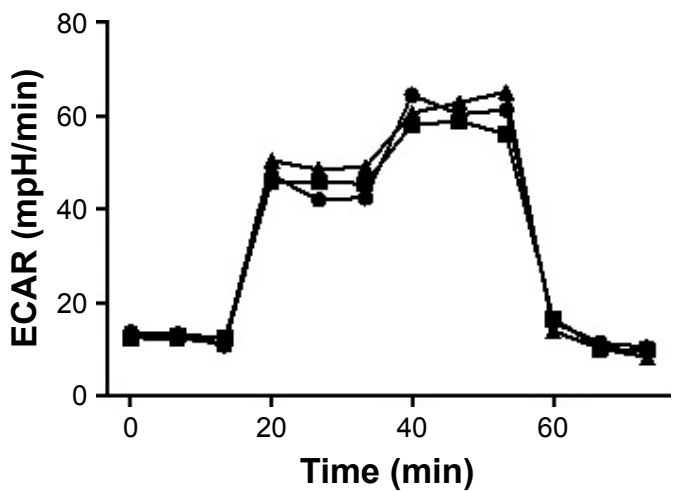
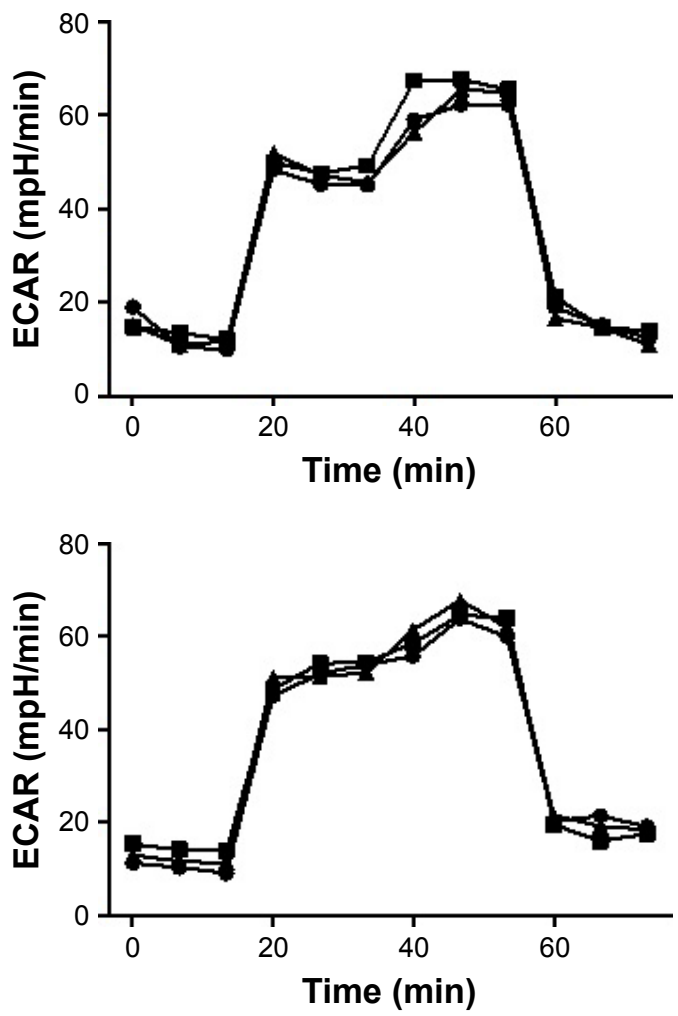

Control

Liraglutide

Exenatide

Figure 7 Effects of GLP-IR agonists on mitochondrial respiration and glycolysis in PTC cell lines.

Notes: PTC cells were treated with liraglutide or exenatide (I00 nmol/L) for $48 \mathrm{~h}$. Oligomycin $(\mathrm{I} \mu \mathrm{M})$, FCCP $(0.25 \mu \mathrm{M})$, rotenone $(\mathrm{I} \mu \mathrm{M})$, and antimycin A $(\mathrm{I} \mu \mathrm{M}) \mathrm{were}$ delivered at the indicated times to determine different parameters of mitochondrial functions; glucose (I0 mM), oligomycin (I.0 $\mu$ M), and 2-deoxy-D-glucose (I00 mM) were delivered at indicated times to determine different parameters of glycolysis status. These drugs were added according to the manufacturer's protocols. (A) IHH4, (B) BCPAP, and (C) TPC-I.

Abbreviations: BCPAP, normal human thyroid cells; ECAR, extracellular acidification rate; FCCP, P-trifluoromethoxyphenylhydrazone; GLP-IR, glucagon-like peptide-I receptor; IHH4, human papillary thyroid carcinoma cell line; OCR, oxygen consumption rate; PTC, papillary thyroid cancer; TPC-I, human thyroid cancer cell line.

glucose metabolism, has been commonly observed in a wide range of human cancers, including PTC..$^{13}$ Accumulation of lactate from the aerobic glycolysis forms an acidic environment to facilitate tumor invasion. ${ }^{32}$ In addition, Lee et al suggested that there were alterations in mitochondrial respiration and glycolysis in thyroid cancer cell lines and found that the expression of mitochondrial ribosomal protein 44 might be a representative marker of the metabolic phenotype and a useful predictor of lymph node metastasis in PTC. ${ }^{33}$
Accordingly, in our study, to provide additional evidence for the safety of insulin analogs and GLP-1R agonists, we systematically analyzed effects of these antidiabetic agents on mitochondrial respiration and glycolysis in PTC cell lines. However, the insulin analogs and GLP-1R agonists did not show any capacity to change cell energetics in vitro.

The limitations of the present study include the following: first, we were unable to collect adequate clinical data, such as the patient's history of diabetes mellitus, serum 
insulin/IGF-1/GLP-1 levels, and the use of any antidiabetic agents. Therefore, it was impossible to perform a patient-level analysis on the association of insulin and GLP-1 with the development of PTC. Second, in vitro experiments could not represent exactly what happens in vivo. Nevertheless, in vitro studies are necessary and generally accepted to provide safety information for antidiabetic agents.

\section{Conclusion}

Both PTC tissues and the PTC cell lines express IR, IGF-1R, and GLP-1R. However, insulin analogs and GLP-1R agonists may not influence cell proliferation, PI3K/Akt and MAPK/ Erk signaling, or energy metabolism in PTC cells. For now, we believe it is not necessary to avoid the use of these antidiabetic agents in patients with PTC. However, in this study, the subtypes of PTC cell lines used were unknown. For indolent types of PTC, antidiabetic medications may have an influence on their proliferation; however, the situation might be different for other PTC subtypes. Thus, long-term cohort observations are needed to confirm the safety of these agents in patients with PTC, especially those with aggressive subtypes.

\section{Ethics approval and consent to participate}

Our study protocol was approved by the Ethics Committee of The First Affiliated Hospital of China Medical University, Shenyang, China. Written informed consent was obtained from all study participants.

\section{Acknowledgments}

This work was supported by the Liaoning Provincial Natural Science Foundation (grant number 2014021039), the Clinical Medical Research Fund of Chinese Medical Association (grant numbers 13050810466 and 13040480433), and the Growth Plan for Distinguished Young Scholars in Universities of Liaoning Province, China (grant number LJQ2015114).

\section{Disclosure}

The authors report no conflicts of interest in this work.

\section{References}

1. Chen $\mathrm{W}$, Zheng R, Baade PD, et al. Cancer statistics in China, 2015. CA Cancer J Clin. 2016;66(2):115-132.

2. Zhou Y, Zhang X, Gu C, Xia J. Diabetes mellitus is associated with breast cancer: systematic review, meta-analysis, and in silico reproduction. Panminerva Med. 2015;57(3):101-108.

3. Huxley R, Ansary-Moghaddam A, Berrington de Gonzalez A, Barzi F, Woodward M. Type-II diabetes and pancreatic cancer: a meta-analysis of 36 studies. Br J Cancer. 2005;92(11):2076-2083.
4. Guraya SY. Association of type 2 diabetes mellitus and the risk of colorectal cancer: a meta-analysis and systematic review. World $J$ Gastroenterol. 2015;21(19):6026-6031.

5. Fang H, Yao B, Yan Y, et al. Diabetes mellitus increases the risk of bladder cancer: an updated meta-analysis of observational studies. Diabetes Technol Ther. 2013;15(11):914-922.

6. El-Serag HB, Hampel H, Javadi F. The association between diabetes and hepatocellular carcinoma: a systematic review of epidemiologic evidence. Clin Gastroenterol Hepatol. 2006;4(3):369-380.

7. Jonasson JM, Ljung R, Talback M, Haglund B, Gudbjornsdottir S, Steineck G. Insulin glargine use and short-term incidence of malignancies-a population-based follow-up study in Sweden. Diabetologia. 2009;52(9):1745-1754.

8. Adami HO, McLaughlin J, Ekbom A, et al. Cancer risk in patients with diabetes mellitus. Cancer Causes Control. 1991;2(5):307-314.

9. Shih SR, Chiu WY, Chang TC, Tseng CH. Diabetes and thyroid cancer risk: literature review. Exp Diabetes Res. 2012;2012:578285.

10. Bjerre Knudsen L, Madsen LW, Andersen S, et al. Glucagon-like Peptide-1 receptor agonists activate rodent thyroid C-cells causing calcitonin release and C-cell proliferation. Endocrinology. 2010;151(4): 1473-1486.

11. Lovshin JA, Drucker DJ. Incretin-based therapies for type 2 diabetes mellitus. Nat Rev Endocrinol. 2009;5(5):262-269.

12. Shelton JG, Steelman LS, White ER, McCubrey JA. Synergy between $\mathrm{PI} 3 \mathrm{~K} / \mathrm{Akt}$ and Raf/MEK/ERK pathways in IGF-1R mediated cell cycle progression and prevention of apoptosis in hematopoietic cells. Cell Cycle. 2004;3(3):372-379.

13. Feng C, Gao Y, Wang C, et al. Aberrant overexpression of pyruvate kinase M2 is associated with aggressive tumor features and the BRAF mutation in papillary thyroid cancer. J Clin Endocrinol Metab. 2013;98(9):E1524-E1533.

14. Karlstad O, Starup Linde J, Vestergaard P, et al. Use of insulin and insulin analogs and risk of cancer; systematic review and meta-analysis of observational studies. Curr Drug Saf. 2013;8(5):333-348.

15. Hsieh MC, Lee TC, Cheng SM, Tu ST, Yen MH, Tseng CH. The influence of type 2 diabetes and glucose-lowering therapies on cancer risk in the Taiwanese. Exp Diabetes Res. 2012;2012:413782.

16. Carstensen B, Witte DR, Friis S. Cancer occurrence in Danish diabetic patients: duration and insulin effects. Diabetologia. 2011;55(4): 948-958.

17. Habel LA, Danforth KN, Quesenberry CP, et al. Cohort study of insulin glargine and risk of breast, prostate, and colorectal cancer among patients with diabetes. Diabetes Care. 2013;36(12):3953-3960.

18. Drejer K. The bioactivity of insulin analogs from in vitro receptor binding to in vivo glucose uptake. Diabetes Metab Rev. 1992;8(3):259-285.

19. Weinstein D, Simon M, Yehezkel E, Laron Z, Werner H. Insulin analogs display IGF-I-like mitogenic and anti-apoptotic activities in cultured cancer cells. Diabetes Metab Res Rev. 2009;25(1):41-49.

20. Shukla A, Grisouard J, Ehemann V, Hermani A, Enzmann H, Mayer D. Analysis of signaling pathways related to cell proliferation stimulated by insulin analogs in human mammary epithelial cell lines. Endocr Relat Cancer. 2009;16(2):429-441.

21. Sciacca L, Le Moli R, Vigneri R. Insulin analogs and cancer. Front Endocrinol (Lausanne). 2012;3:21.

22. Liu YJ, Qiang W, Shi J, Lv SQ, Ji MJ, Shi BY. Expression and significance of IGF-1 and IGF-1R in thyroid nodules. Endocrine. 2013; 44(1):158-164.

23. Schmidt JA, Allen NE, Almquist M, et al. Insulin-like growth factor-I and risk of differentiated thyroid carcinoma in the European prospective investigation into cancer and nutrition. Cancer Epidemiol Biomarkers Prev. 2014;23(6):976-985.

24. Rouse R, Xu L, Stewart S, Zhang J. High fat diet and GLP-1 drugs induce pancreatic injury in mice. Toxicol Appl Pharmacol. 2014;276(2): 104-114.

25. Elashoff M, Matveyenko AV, Gier B, Elashoff R, Butler PC. Pancreatitis, pancreatic, and thyroid cancer with glucagon-like peptide-1-based therapies. Gastroenterology. 2011;141(1):150-156. 
26. Zhao H, Wang L, Wei R, et al. Activation of glucagon-like peptide-1 receptor inhibits tumourigenicity and metastasis of human pancreatic cancer cells via PI3K/Akt pathway. Diabetes Obes Metab. 2014;16(9): 850-860.

27. Gier B, Butler PC, Lai CK, Kirakossian D, DeNicola MM, Yeh MW. Glucagon like peptide-1 receptor expression in the human thyroid gland. J Clin Endocrinol Metab. 2012;97(1):121-131.

28. Fang D, Huang Z, Guan H, et al. The Akt/FoxO1/p27 pathway mediates the proliferative action of liraglutide in beta cells. Mol Med Rep. 2012;5(1):233-238.

29. Wei Q, Sun YQ, Zhang J. Exendin-4, a glucagon-like peptide-1 receptor agonist, inhibits cell apoptosis induced by lipotoxicity in pancreatic beta-cell line. Peptides. 2012;37(1):18-24.
30. Challa TD, Beaton N, Arnold M, Rudofsky G, Langhans W, Wolfrum C. Regulation of adipocyte formation by GLP-1/GLP-1R signaling. J Biol Chem. 2012;287(9):6421-6430.

31. Chang WW, Lin RJ, Yu J, et al. The expression and significance of insulin-like growth factor-1 receptor and its pathway on breast cancer stem/progenitors. Breast Cancer Res. 2013;15(3):R39.

32. Hanahan D, Weinberg RA. Hallmarks of cancer: the next generation. Cell. 2011;144(5):646-674.

33. Lee J, Seol MY, Jeong S, et al. A metabolic phenotype based on mitochondrial ribosomal protein expression as a predictor of lymph node metastasis in papillary thyroid carcinoma. Medicine (Baltimore) 2015;94(2):e380.

\section{Publish your work in this journal}

OncoTargets and Therapy is an international, peer-reviewed, open access journal focusing on the pathological basis of all cancers, potential targets for therapy and treatment protocols employed to improve the management of cancer patients. The journal also focuses on the impact of management programs and new therapeutic agents and protocols on

\section{Dovepress}

patient perspectives such as quality of life, adherence and satisfaction. The manuscript management system is completely online and includes a very quick and fair peer-review system, which is all easy to use. Visit http://www.dovepress.com/testimonials.php to read real quotes from published authors.

Submit your manuscript here: http://www.dovepress.com/oncotargets-and-therapy-journal 